\begin{tabular}{ccc}
\hline & $\begin{array}{c}\text { International Journal of Health Services } \\
\text { Research and Policy } \\
\text { www.dergipark.org.tr/ijhsrp }\end{array}$ \\
$\begin{array}{c}\text { INESEG } \\
\text { ENGINETIONAL } \\
\text { SCIENCE ANG } \\
\text { EDUCATION GROUP }\end{array}$ & e-ISSN: $2602-3482$ & IJHSRP \\
\hline
\end{tabular}

Review Article

\title{
FACTORS AFFECTING NURSES' JOB SATISFACTION IN MEDICAL SURGICAL NURSING CARE IN TURKEY: A SYSTEMATIC REVIEW
}

\author{
Abdallah ALWAWI ${ }^{1.2^{*}(1)}$ Ayşegül KOÇ ${ }^{3}$ (i) Bahar INNAYA ${ }^{4}$ \\ ${ }^{1}$ Ankara Yıldırım Beyazıt University, Turkey \\ ${ }^{2}$ Department of Nursing, College of Health Professions, Al-Quds University, Abu Dies, Jerusalem, Palestine \\ ${ }^{3}$ Faculty of Health Sciences, Yıldırım Beyazıt University, Ankara, Turkey \\ ${ }^{4}$ Faculty of Health Sciences, Yıldırım Beyazıt University, Ankara, Turkey \\ *Corresponding author: aalwawi@staff.alquds.edu
}

\begin{abstract}
Job-related satisfaction has the likelihood of improving the care provided by nurses within the health settings. Nurses' job satisfaction is likely to boost quality healthcare services and their commitment level. Several factors inform the job satisfaction of nurses, such as fair promotion opportunities, retention, and fringe benefits. The study aimed to explore the main factors impacting medical-surgical nurses' job satisfaction. The existing literature revealed that work satisfaction among nurses is affected by a number of aspects. A systematic review of studies was conducted. A total of $(n=40)$ studies were eligible for inclusion. Preferred Reporting Items for Systematic reviews and MetaAnalyses (PRISMA) guidelines were used to report and examine the eligibility of various studies. The systematic review indicated the factors could be classified into four categories, including extrinsic, intrinsic, personal, and community factors. The extrinsic factors include working conditions, work environment, supervisor/management, burnout, work engagement, and mobbing/bullying. The main intrinsic factors were found to include professionalism and career identity. Personal factors included marital status, age, and level of education, whereas economic status was found to be the only community factor influencing the satisfaction of medical-surgical nurses. The main factors influencing medicalsurgical nurses include extrinsic, intrinsic, personal, and community.
\end{abstract}

Keywords: Job Satisfaction, medical-surgical nurses, intrinsic factors, and extrinsic factors

Received: June 7, $2020 \quad$ Accepted: July 8,2020

\section{Introduction}

Job-related satisfaction has the likelihood of improving care provided by nurses within the health settings. Nurses' job satisfaction is likely to boost quality healthcare services and their commitment level [1]. Low satisfaction results in poor healthcare services and shapes the intention to leave the hospital. Thus, the satisfaction of nurses is considered to be the primary determinant of sustainable quality patient care and retention of these professionals [2]. Job satisfaction is a significant issue affecting nurses in surgical care or wards. Job satisfaction among these professionals has been 
linked to the availability of professional development opportunities, promotion, and achievements [3]. Job-related satisfaction is an extremely subjective concept and is consequently complex and multidimensional [4]. research studies connect numerous aspects to nurses' job-related satisfaction in various clinical working settings and various nations [5].

Job satisfaction is mainly determined by actual job experiences together with expectations concerning the job. There are varying job satisfaction levels among nursing professionals. However, the predictors of job satisfaction among nurses are fairly common, and entail working conditions, promotion, working hours, and pay, and others [6]. Nurses form the primary workforce responsible for protection, improvement, and promotion of the population's health [7]. Thus, their job satisfaction is considered to be paramount Job satisfaction among nurses is mainly impacted by both extrinsic and intrinsic factors [8]. Herzberg's theory shall guide the study. The model suggested that job-related satisfaction is affected by two key sets of elements, namely intrinsic factors, and extrinsic factors. Some of the extrinsic factors include working conditions, interpersonal relations, and quality of supervision. The main intrinsic factors are responsible, the nature of work, individual growth, achievement, as well as recognition [9]. The review of the past study indicated that numerous studies had been conducted concerning job satisfaction among medical surgical nursing care setting nurses. However, the researcher noted that there is no systematic review that has been done to determine factors affecting nurses' job satisfaction in medical surgical nursing care in the context of Turkey. The researcher hopes to inform stakeholders in medical surgical nursing care about the main factors affecting nurses' job satisfaction. Variations in extrinsic, intrinsic, personal, and community factors and expectations that are associated with the clinical departments may affect nurses' job satisfaction. Therefore, our study question used to handle the research was: What are the factors linked with job-related satisfaction for nurses working in medical-surgical settings in the context of Turkey?

\subsection{Aims}

The main aim of the review is to present a systematic and meta-analysis of research examining factors affecting nursing professionals' job satisfaction within medical surgical nursing care. The study aimed to identify extrinsic, intrinsic, personal, and community factors that impact job satisfaction amongst nursing professionals working in medical-surgical care settings.

\section{Materials and Methods}

The study employed Preferred Reporting Items for Systematic reviews and Meta-Analyses (PRISMA) guidelines. The guidelines were used to report and examined various studies. The guideline helped in ensuring quality reporting of studies related to the area of interest. PRISMA guidelines also ensured that the systematic and meta-analysis were limited to the scope of Turkey and the medicalsurgical care setting.

\subsection{Search Methods}

The search for relevant literature was done between March 25 and 28, 2019. The search process was limited to randomized applied studies and theses, focusing on nurses' job satisfaction within medical and surgical care settings. The search was carried using various online academic databases, including Ebscohost, Proquest, PubMed, Scopus, CINAHL, Embase, Emerald, MJ Clinical Evidence, 
PsycINFO, and Web of Science. The search was also done in a doctoral and master's theses databases in Turkey. Several search terms were used to enable search as well as retrieval of appropriate studies in the online databases, as mentioned above. The search terms included medical-surgical care nurses, job satisfaction among nursing professionals in medical-surgical settings, job satisfaction,' and 'medical surgical nursing care in Turkey.' Boolean operators "AND" and "OR" were also used.

\subsection{Inclusion and Exclusion Criteria}

Current study limited to journal articles and theses related to medical surgical nursing care settings. Studies using other designs not relevant were also included. It was further restricted to work published from 1995 to 2020 . The inclusion criteria were studies focusing on nurses in medical-surgical care settings in Turkey. Studies were also eligible for review if they offered comprehensive information concerning factors affecting nurses' job satisfaction within medical surgical nursing care settings. Studies were excluded if their scope was not limited in Turkey's medical-surgical care settings. They were also excluded if they focused on general nurses in Turkey. Studies published below 1995 were also excluded.

\subsection{Search Outcomes}

The search yielded 1400 references $(n=1400)$ from the databases mentioned above. The full copies of the eligible studies for inclusion were retrieved and further assessed for their relevance. The abstracts were analyzed to gather insights regarding the methodology used in each study and results. Duplicated articles were excluded $(n=800)$, and 600 verified based on the area of research. The manual cross-checking led to the expulsion of $(n=400)$ as they failed to fulfill the set inclusion criteria. A total of $(n=200)$ copies were excluded as they did not address the subject area, and the remaining $(n=200)$ were thoroughly examined for and $(n=100)$ excluded as they did not focus on nurses in Turkey medicalsurgical care setting. Sixty $(\mathrm{n}=60)$ studies were omitted as they emerged to be copied, and the rest $(\mathrm{n}=40)$ qualified for inclusion. A summary of the retrieved studies was presented based on PRISMA guidelines, as demonstrated in Figure 1. 


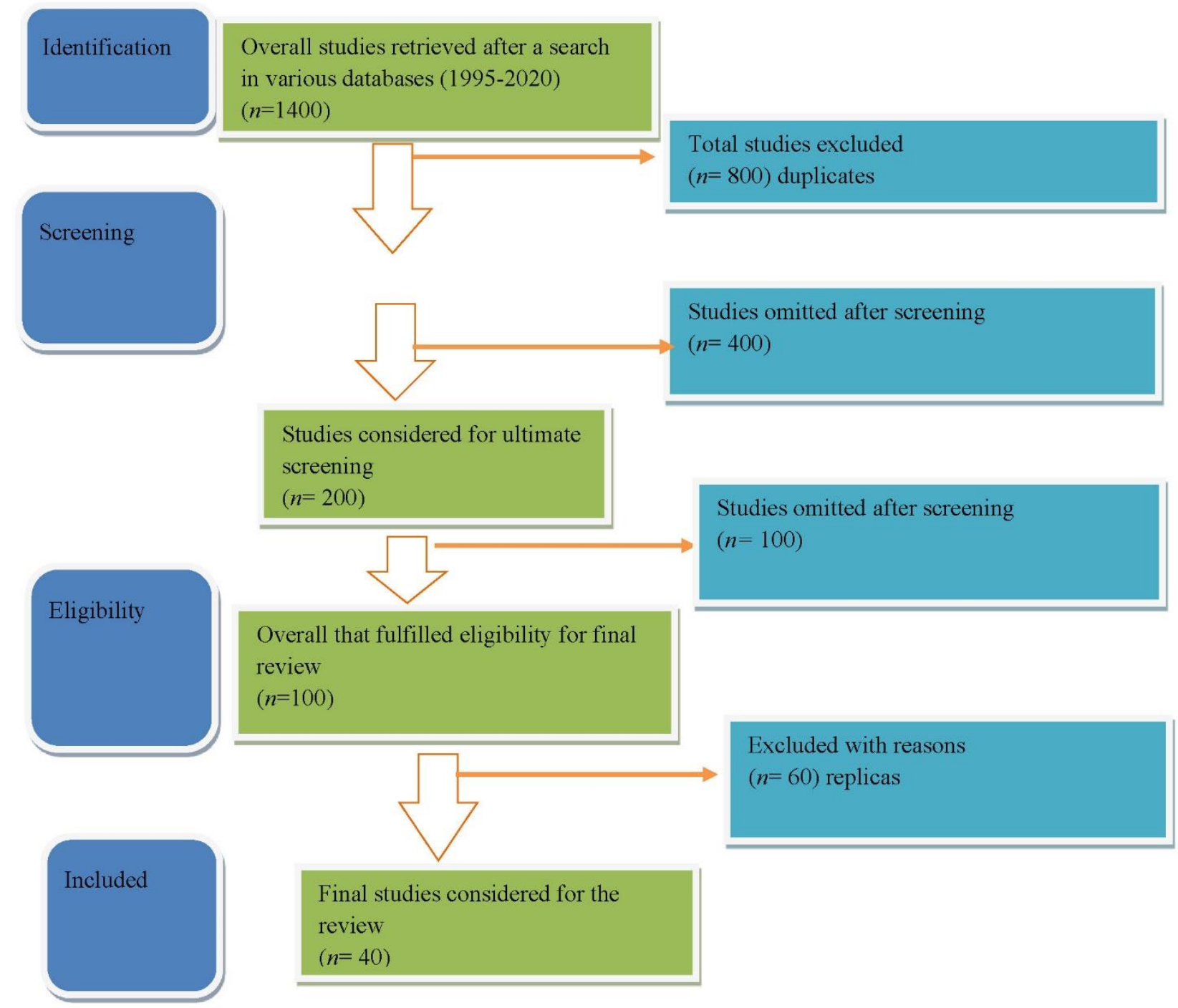

Figure 1. PRISMA guidelines.

\subsection{Quality Appraisal}

Two independent reviewers examined the selected studies. The study also utilized the Joanna Briggs Institute (JBI) to facilitate the appraisal of the quality of selected studies. The selected studies were subjected to rigorous appraisal by two critical appraisers. The evaluation informed both synthesis and explanations of the study's findings. An assessment of risk bias was also conducted, as indicated in Table 1. 
Table 1. Assessment of risk bias for the selected research articles.

\begin{tabular}{|c|c|c|c|c|c|}
\hline Studies & $\begin{array}{l}\text { Are the } \\
\text { inclusion } \\
\text { criteria of } \\
\text { participants } \\
\text { clearly } \\
\text { indicated? }\end{array}$ & $\begin{array}{l}\text { Were the } \\
\text { participants } \\
\text { and settings } \\
\text { thoroughly } \\
\text { described? }\end{array}$ & $\begin{array}{l}\text { Were job } \\
\text { satisfaction } \\
\text { factors } \\
\text { measured? }\end{array}$ & $\begin{array}{l}\text { Were the } \\
\text { studies' } \\
\text { outcomes } \\
\text { measured } \\
\text { in a valid } \\
\text { as well as } \\
\text { a reliable } \\
\text { way? }\end{array}$ & $\begin{array}{l}\text { Was a } \\
\text { suitable } \\
\text { statistical } \\
\text { approach } \\
\text { employed? }\end{array}$ \\
\hline Burke et al., 2012 & $\checkmark$ & $\checkmark$ & $\checkmark$ & $\checkmark$ & $\checkmark$ \\
\hline Cilingir et al., 2012 & $\checkmark$ & $\checkmark$ & $\checkmark$ & $\checkmark$ & $\checkmark$ \\
\hline $\begin{array}{l}\text { Torun and Cavusoglu, } \\
2018\end{array}$ & $\checkmark$ & $\checkmark$ & $\checkmark$ & $\checkmark$ & $\checkmark$ \\
\hline Uğurlu et al., 2015 & $\checkmark$ & $\checkmark$ & $\checkmark$ & $\checkmark$ & $\checkmark$ \\
\hline $\begin{array}{l}\text { Sabanciogullari and } \\
\text { Dogan, } 2017\end{array}$ & $\checkmark$ & $\checkmark$ & $\checkmark$ & $\checkmark$ & $\checkmark$ \\
\hline Çelik and Hisar, 2012 & $\checkmark$ & $\checkmark$ & $\checkmark$ & $\checkmark$ & $\checkmark$ \\
\hline Tural et al., 2015 & $\checkmark$ & $\checkmark$ & $\checkmark$ & $\checkmark$ & $\checkmark$ \\
\hline $\begin{array}{l}\text { Cimete, Gencalp, and } \\
\text { Keskin, 2003) }\end{array}$ & $\checkmark$ & $\checkmark$ & $\checkmark$ & & \\
\hline Ariza-Montes & & $\checkmark$ & & $\checkmark$ & $\checkmark$ \\
\hline $\begin{array}{l}\text { Bardakçı and Günüşen, } \\
2016 .\end{array}$ & $\checkmark$ & & $\checkmark$ & $\checkmark$ & $\checkmark$ \\
\hline Çevik et al., 2012 & & $\checkmark$ & $\checkmark$ & $\checkmark$ & $\checkmark$ \\
\hline Cilingir et al., 2012 & $\checkmark$ & $\checkmark$ & $\checkmark$ & $\checkmark$ & $\checkmark$ \\
\hline Efe and Ayaz, 2010 & & & $\checkmark$ & $\checkmark$ & $\checkmark$ \\
\hline Ekici et al.,2017 & & & $\checkmark$ & $\checkmark$ & $\checkmark$ \\
\hline Emhan, 2012 & $\checkmark$ & $\checkmark$ & $\checkmark$ & & $\checkmark$ \\
\hline Er and Sökmen, 2018 & & $\checkmark$ & $\checkmark$ & $\checkmark$ & $\checkmark$ \\
\hline Gok et al., 2015 & & $\checkmark$ & $\checkmark$ & $\checkmark$ & $\checkmark$ \\
\hline Goris et al., 2016 & $\checkmark$ & $\checkmark$ & $\checkmark$ & $\checkmark$ & $\checkmark$ \\
\hline Montgomery et al., 2015. & $\checkmark$ & $\checkmark$ & $\checkmark$ & & $\checkmark$ \\
\hline $\begin{array}{l}\text { Ofluoğlu and Somunoğlu, } \\
2012\end{array}$ & $\checkmark$ & & $\checkmark$ & $\checkmark$ & $\checkmark$ \\
\hline Özer et al., 2017. & $\checkmark$ & & $\checkmark$ & $\checkmark$ & $\checkmark$ \\
\hline Ucuk and Yurtsal, 2017. & $\checkmark$ & $\checkmark$ & $\checkmark$ & $\checkmark$ & $\checkmark$ \\
\hline $\begin{array}{l}\text { Yildirim and Yildirim, } \\
2007 .\end{array}$ & $\checkmark$ & $\checkmark$ & $\checkmark$ & $\checkmark$ & $\checkmark$ \\
\hline Yildırım, 2009. & $\checkmark$ & $\checkmark$ & $\checkmark$ & $\checkmark$ & $\checkmark$ \\
\hline Yildiz et al., 2009. & $\checkmark$ & $\checkmark$ & $\checkmark$ & $\checkmark$ & $\checkmark$ \\
\hline $\begin{array}{l}\text { Yurumezoglu and } \\
\text { Kocaman, 2012. }\end{array}$ & $\checkmark$ & $\checkmark$ & $\checkmark$ & $\checkmark$ & $\checkmark$ \\
\hline Seren Intepeler et al., 2019 & $\checkmark$ & $\checkmark$ & $\checkmark$ & $\checkmark$ & $\checkmark$ \\
\hline Korhan et al., 2014 & $\checkmark$ & $\checkmark$ & $\checkmark$ & $\checkmark$ & $\checkmark$ \\
\hline Aksakal et al., 2015 & $\checkmark$ & $\checkmark$ & $\checkmark$ & $\checkmark$ & $\checkmark$ \\
\hline Palaz, 2013 & $\checkmark$ & $\checkmark$ & $\checkmark$ & $\checkmark$ & $\checkmark$ \\
\hline Seyrek and Ekici, 2017 & & $\checkmark$ & $\checkmark$ & $\checkmark$ & $\checkmark$ \\
\hline $\begin{array}{l}\text { Burke, Koyuncu, and } \\
\text { Fiksenbaum, } 2010\end{array}$ & $\checkmark$ & $\checkmark$ & $\checkmark$ & $\checkmark$ & $\checkmark$ \\
\hline Orsal et al., 2017 & $\checkmark$ & $\checkmark$ & $\checkmark$ & $\checkmark$ & $\checkmark$ \\
\hline Danaci and Koç, 2019 & & $\checkmark$ & $\checkmark$ & $\checkmark$ & $\checkmark$ \\
\hline
\end{tabular}


Table 1. (continued)

\begin{tabular}{|l|c|c|c|c|c|}
\hline $\begin{array}{l}\text { Arslan Yurumezoglu and } \\
\text { Kocaman,2016 }\end{array}$ & $\checkmark$ & $\checkmark$ & $\checkmark$ & $\checkmark$ & $\checkmark$ \\
\hline Cagan and Gunay, 2015 & $\checkmark$ & $\checkmark$ & $\checkmark$ & $\checkmark$ & $\checkmark$ \\
\hline Erdem et al., 2008 & $\checkmark$ & & $\checkmark$ & & $\checkmark$ \\
\hline $\begin{array}{l}\text { Sabanc10gullari and } \\
\text { Dogan, 2015a }\end{array}$ & $\checkmark$ & & $\checkmark$ & $\checkmark$ & $\checkmark$ \\
\hline $\begin{array}{l}\text { Sönmez and Yildirim, } \\
2018\end{array}$ & $\checkmark$ & $\checkmark$ & $\checkmark$ & $\checkmark$ & $\checkmark$ \\
\hline $\begin{array}{l}\text { Sabanciogullari and } \\
\text { Dogan 2015b }\end{array}$ & $\checkmark$ & $\checkmark$ & $\checkmark$ & $\checkmark$ & $\checkmark$ \\
\hline
\end{tabular}

\subsection{Data Abstraction and Synthesis}

The author conducted the data extraction. The primary data extracted for this particular systematic review included journal, country, authors, population, setting, purpose, and research questions. Others included sample, data collection instruments, and main findings of the studies, sampling technique, and response rate. Thematic analysis was used to extract and present the needed data.

\section{Results}

\section{Study Characteristics}

Various studies involving medical-surgical nurses were included in this systematic and metaanalysis. The studies included cross-sectional, descriptive, and longitudinal. All the studies included were conducted within Turkey's medical surgical nursing care center.

\subsection{Extrinsic Factors Affecting Job Satisfaction}

The reviewed studies associated work engagement with enhanced job satisfaction among medical-surgical care nurses $[10,11]$. There is substantial evidence that work engagement impacts Turkish nurses' job satisfaction [12]. Burnout was also found to adversely affect nursing professionals' work satisfaction [15]. A study reported that level burnout on job satisfaction using a sample of 330 surgical and medical ward nurses in a hospital situated in northeastern Turkey was found to be negatively associated [16]. Burnout was also found to results in low satisfaction with other studies [17, 18].

Nursing professionals in surgical medical care job-related satisfaction was further found to be influenced by working conditions. It was further found to be influenced by the working environment $[19,20]$. A work environment characterized by the sufficiency of both equipment and materials was found to enhance the quality of work-related satisfaction. Supervisor support was revealed as another extrinsic element determining job-related satisfaction of nursing professionals [22, 23]. Higher-level of work satisfaction was reported by nurses being supported by their supervisors [24, 25]. It was further found that mobbing/bullying adversely influences nurses' job satisfaction [28]. It was revealed that mobbing behavior by head nurses adversely impacted work-related satisfaction among the nurses [2931]. Nurses who are the victim of bullying tend to have reduced job satisfaction [32-34]. The likelihood of being bullied by a nurse manager tends to decrease job security and, ultimately, job satisfaction among the nurses[35-37]. 
In summary, the reviewed previous studies indicate that these multiple and different external factors such as work engagement, burnout, working conditions, and environment, supervisor support, mobbing, bullying have played an important role in nurses' job-related satisfaction.

\subsection{Intrinsic Factors Impacting Job-Related Satisfaction}

The reviewed articles showed that career identity is certainly linked to job-related satisfaction amongst medical and surgical nursing professionals in a total of 28 national healthcare settings as well as 14 university health organizations in seven regions across Turkey [38]. It was also found that professionalism was correlated with work-related satisfaction amongst medical/surgical nurses across Turkey $[39,40]$. Professional identity was found to promote job-related satisfaction hence reducing nurses' intent to leave [40].

In summary, the reviewed previous studies indicate that these multiple and different internal factors such as career identity, professionalism, and Professional identity have played an important role in nurses' job-related satisfaction.

\subsection{Personal Factors Affecting Job Satisfaction}

The review indicated that marital status and age influenced work-related satisfaction among medical-surgical nurses working in varying hospitals within Turkey. Job-related fulfillment amongst single medical-surgical nurses aged 40 years and above was found to statistically significant [41]. The educational level was associated with job satisfaction. Medical-surgical nurses with masters and Ph.D. reported higher job satisfaction [42].

In conclusion, recent findings have shown that such numerous and distinct personal variables, such as marital status, age, and educational qualification, have played a significant role in the satisfaction of nurses at work.

\subsection{Community Factors}

It was further found that the economic status of medical-surgical nurses influenced their job satisfaction across Turkey. The low economic level was linked to reduced job satisfaction [42]. Consequently, the economic level factor has played an important and real role in the job-related satisfaction of the nurses.

\section{Discussion}

The study focused on examining factors influencing medical surgical nursing professionals' job satisfaction utilizing journal articles published from 1995 to 2020. The results of the study were examined through the lens of Herzberg's model. The job satisfaction influencing factors were categorized into four main categories, including extrinsic, intrinsic, community, as well as personal. The review was limited to medical-surgical nurses in Turkey. The findings demonstrated that work-related burnout was the main extrinsic job satisfaction factor [16]. Other identified extrinsic factors include working conditions [43] and work engagement. A nurse's work satisfaction job was further linked with supervisor support [22] mobbing [28] and bullying [37].

The findings also highlighted that the common intrinsic factors influencing job satisfaction among medical-surgical nurses include career identity and professionalism [39]. Different personal aspects were demonstrated to determine job satisfaction among medical-surgical nurses in Turkey. The 
main factors found to be marital factors and age [41] and level of education [42]. Lastly, the primary community factor found to influence the satisfaction of medical-surgical nurses is the economic status [42]. The results demonstrate that various factors influence medical-surgical nurses' job satisfaction, and hence hospital administrators and managers should be close attention to these factors. Especially nurses are particularly profoundly active in patient care and have a significant wide role.

The measurement methods and tools for predictors and results were difficult to define and have not sometimes been recorded for their reliability and validity. It will influence the study's internal and external validity. Consequently, causal inferences cannot be made from the analysis, and thus the interpretation of the observations must be viewed in the context of this significant caution. Studies on the variations between variables impacting the job satisfaction of nurses in medical-surgical settings remains a gap. More work into this subject will help organizations to adapt their strategies depending on their position to increase job satisfaction for medical-surgical nurses. This analysis offers scientific evidence for the theory of Herzberg. Herzberg's hypothesis can offer analytical insight into the effect on medical-surgical nurses' satisfaction with both intrinsic and extrinsic influences.

\section{Limitations of the Research}

Though focused on standardized and accepted methods, this analysis has several drawbacks. It contained just English language articles spanning the past two decades. In comparison, grey publications and unpublished research have not been recovered, which omitted possibly valuable knowledge outlets which suggest that the findings do not reflect all valid study in this area. Moreover, the researcher found minimal studies focusing on medical surgical nursing care. The researcher was also unable to find randomized applied studies for the current review.

\section{Conclusion}

The main aim of this systematic review was to explore factors affecting nurses' job satisfaction in medical surgical nursing care in turkey. Several available studies have discussed the factors considered to be associated with medical-surgical nurses' job satisfaction around the world but unfortunately, there are not in Turkey. Researches on the variations among variables affecting the jobrelated satisfaction of nurses in medical-surgical settings remains a gap. Although these nurses have a unique, broad, and intensive role in daily care for different types of patients. Further research into this subject might support organizations to make their plans to enhance medical-surgical nurses' job-related satisfaction based on their workplaces.

The existing literature revealed that job satisfaction among nurses is affected by several important factors. The review indicated that the work environment, supervisor/management, burnout, work engagement, mobbing/bullying, professional identity, marital status, age, educational qualification, and the economic level are the main factors influencing nursing satisfaction in medicalsurgical departments in Turkey. Nevertheless, the researcher found minimal studies focusing on medical surgical nursing care. The researcher was also unable to find randomized applied studies for the current review.

It is important to pay attention to these important factors. The researchers recommend that hospitals and nursing managers must design and execute approaches and strategies that maximize the efficacy of these important different factors. It should always be remembered that neither personal, 
economic nor intrinsic, extrinsic factors alone are considered to be sufficient to reduce job-related dissatisfaction among medical-surgical nurses. Rather, It is important to focus on them together to achieve the best results.

\section{References}

[1] A. K. M. Masum, Azad, M. A. K., Hoque, K. E., Beh, L. S., Wanke, P., \& Arslan, Ö., "Job satisfaction and intention to quit: an empirical analysis of nurses in Turkey", The Journal of Life and Environmental Sciences, 4, 1-23, 2016.

[2] S. Kapucu, Kose, T. K., Kurt, B., \& Ersoy, N. A., "Attitudes and satisfaction of nurses with the work environment in Turkey," International Journal of Caring Sciences, 10(2), 771-780, 2017.

[3] L. Serafin, Bjerså, K., \& Doboszynska, A, "Nurse job satisfaction at a surgical ward-A comparative study between Sweden and Poland," Medycyna Pracy, 70(2), 155-167, 2019.

[4] B. Hayes, A. Bonner, and J. Pryor, "Factors contributing to nurse job satisfaction in the acute hospital setting: a review of recent literature," Journal of Nursing Management, 18(7), 804-814, 2010.

[5] M. J. Derby-Davis, "Predictors of nursing faculty's job satisfaction and intent to stay in academe," Journal of Professional Nursing, 30(1), 19-25, 2014.

[6] M. Lorber, \& Skela Savič, B., "Job satisfaction of nurses and identifying factors of job satisfaction in Slovenian Hospitals," Croatian Medical Journal, 53(3), 263-270, 2012.

[7] D. Ekici, Cerit, K., \& Mert, T., "Factors that influence nurses' work-family conflict, job satisfaction, and intention to leave in a private hospital in Turkey," Hospital Practices and Research, 2(4), 102-108, 2017.

[8] D. Hegney, Plank, A., \& Parker, V., "Extrinsic and intrinsic work values: their impact on job satisfaction in nursing," Journal of Nursing Management, 14(4), 271-281, 2006.

[9] F. Herzberg, Mausner, B., \& Snydermann B., The motivation to work, 1959.

[10] A. Montgomery, Spânu, F., Băban, A., \& Panagopoulou, E., "Job demands, burnout, and engagement among nurses: A multi-level analysis of ORCAB data investigating the moderating effect of teamwork," Burnout Research, 2(2), 71-79, 2015.

[11] Ö. Özer, Uğurluoğlu, Ö., \& Saygili, M., "Effect of organizational justice on work engagement in the healthcare sector of Turkey," Journal of Health Management, 19(1), 73-83, 2017.

[12] R. J. Burke, Koyuncu, M., Tekinkuş, M., Bektaş, Ç., \& Fiksenbaum, L., "Work engagement among nurses in Turkish hospitals: Potential antecedents and consequences," ISGUC The Journal of Industrial Relations and Human Resources, 14(1), 7-24, 2012.

[13] H. Arslan Yurumezoglu, \& Kocaman, G., "Predictors of nurses' intentions to leave the organization and the profession in Turkey," Journal of Nursing Management, 24(2), 235-243, 2016.

[14] O. Cagan, \& Gunay, O., "The job satisfaction and burnout levels of primary care health workers in the province of Malatya in Turkey," Pakistan Journal of Medical Sciences, 31(3), 543-547, 2015. 
[15] R. Erdem, Rahman, S., Avc1, L., Göktaş, B., Şenoğlu, B., \& Firat, G., "Investigating Job Satisfaction and Burnout Levels of the Persons Working for the Hospitals at City Center of Elaziğ, Turke," Journal of Applied Science Research, 4(2), 188-201, 2008.

[16] D. Cilingir, Gursoy, A. A., \& Colak, A., "Burnout and job satisfaction in surgical nurses and other ward nurses in a tertiary hospital: A comparative study in Turkey," HealthMed, 6(9), 3120-3128, 2012.

[17] R. J. Burke, M. Koyuncu, and L. Fiksenbaum, "Burnout, work satisfaction and psychological wellbeing among nurses in Turkish hospitals," Europe's Journal of Psychology, 6(1), 63-81, 2010.

[18] O. Orsal, O. Orsal, P. Duru, A. Unsal, and N. Barlas, "Evaluation of the factors associated with Burnout of nurses working at a state hospital in turkey," Nursing Practice Today, 4(1), 21-34, 2017.

[19] S. Seren Intepeler et al., "Role of job satisfaction and work environment on the organizational commitment of nurses: a cross-sectional study," Contemporary Nurse, 55(4-5), 380-390, 2019.

[20] S. Ucuk and Z. B. Yurtsal, "Job Satisfaction and Motivation Levels of Midwives/Nurses Working in Family Health Centres: A Survey from Turkey," International Journal of Caring Sciences, 10(2), 802, 2017.

[21] F. Er, \& Sökmen, S., "Investigation of the working conditions of nurses in public hospitals on the basis of nurse-friendly hospital criteria," International Journal of Nursing Sciences, 5(2), 206-212, 2018.

[22] A. Emhan, "Relationship among managerial support, job satisfaction and organizational commitment: A comparative study of nonprofit, for-profit and public sectors in Turkey," International Journal of Business, Humanities and Technology, 2(5), 179-190, 2012.

[23] H. A. Yurumezoglu, \& Kocaman, G., " Pilot study for evidence-based nursing management: Improving the levels of job satisfaction, organizational commitment, and intent to leave among nurses in Turkey," Nursing \& Health Sciences, 14(2), 221-228, 2012.

[24] S. Gok, I. Karatuna, and P. O. Karaca, "The role of perceived supervisor support and organizational identification in job satisfaction," Procedia-Social and Behavioral Sciences, 177, 38-42, 2015.

[25] Z. Yıldız, S. Ayhan, and Ş. Erdoğmuş, "The impact of nurses' motivation to work, job satisfaction, and sociodemographic characteristics on the intention to quit their current job: An empirical study in Turkey," Applied Nursing Research, 22(2), 113-118, 2009.

[26] R. Çevik Akyil, Tan, M., Saritaş, S., \& Altuntaş, S., "Levels of mobbing perception among nurses in Eastern Turkey," International Nursing Review, 59(3), 402-408, 2012.

[27] A. Yildirim, \& Yildirim, D., "Mobbing in the workplace by peers and managers: mobbing experienced by nurses working in healthcare facilities in Turkey and its effect on nurses," Journal of Clinical Nursing, 16(8), 1444-1453, 2007.

[28] E. A. Korhan, Guler, E. K., Khorshid, L., \& Eser, I., "Mobbing experienced by nurses working in hospitals: an example of turkey," International Journal of Caring Sciences, 7(2), 642-651, 2014. 
[29] S. Efe and S. Ayaz, "Mobbing against nurses in the workplace in Turkey," International Nursing Review, 57(3), 328-334, 2010.

[30] S. Goris, O. Ceyhan, S. Tasci, G. Sungur, P. Tekinsoy, and F. Cetinkaya, "Mobbing against Nurses in Turkey: How Does it Affect Job Satisfaction," International Journal of Caring Sciences, 9(3), 810-8, 2016.

[31] G. Ofluoğlu and S. Somunoğlu, "Cases of mobbing activities as commonly seen in the healthcare sector in the world and in Turkey," Hospital Topics, 90(4), 98-103, 2012.

[32] A. Ariza-Montes, N. M. Muniz, M. J. Montero-Simó, and R. A. Araque-Padilla, "Workplace bullying among healthcare workers," International Journal of Environmental Research and Public Health, 10(8), 3121-3139, 2013.

[33] E. Bardakçı and N. P. Günüşen, "Influence of workplace bullying on Turkish nurses' psychological distress and nurses' reactions to bullying," Journal of Transcultural Nursing, 27(2), 166-171, 2016.

[34] D. Yıldırım, "Bullying among nurses and its effects," International Nursing Review, 56(4), 504$511,2009$.

[35] F. N. B. Aksakal, E. F. Karaşahin, A. U. Dikmen, E. Avci, and S. Özkan, "Workplace physical violence, verbal violence, and mobbing experienced by nurses at a university hospital," Turkish Journal of Medical Sciences, 45(6), 1360-1368, 2015.

[36] S. Palaz, "Turkish nursing students' perceptions and experiences of bullying behavior in nursing education," Journal of Nursing Education and Practice, 3(1), 23, 2013.

[37] H. Seyrek, \& Ekici, D., "Nurses' Perception of Organisational Justice and its Effect on Bullying Behaviour in the Hospitals of Turkey," Hospital Practices and Research, 2(3), 72-78, 2017.

[38] S. Sabanciogullari, \& Dogan, S., "Nurses' Views on Their Profession in Turkey and Influencing Factors," Arch Nurs Pract Care, 3(1), 016-025, 2017.

[39] S. Çelik and F. Hisar, "The influence of the professionalism behaviour of nurses working in health institutions on job satisfaction," International Journal of Nursing Practice, 18(2), 180-187, 2012.

[40] S. Sabanciogullari, \& Dogan, S., " Effects of the professional identity development programme on the professional identity, job satisfaction and burnout levels of nurses: A pilot study," International Journal of Nursing Practice, 21(6), 847-857, 2015 b.

[41] E. Tural, Rizaral, S., \& Güdek, E., "Ethical sensitivity, job satisfaction and related factors of the nurses working in different areas," Progress in Health Sciences, 5(1), 138-149, 2015.

[42] G. Cimete, Gencalp, N. S., \& Keskin, G., "Quality of life and job satisfaction of nurses," Journal of Nursing Care Quality, 18(2), 151-158, 2003.

[43] Z. Uğurlu, Karahan, A., Ünlü, H., Abbasoğlu, A., Özhan Elbaş, N., Avc1 Işık, S., \& Tepe, A., "The effects of workload and working conditions on operating room nurses and technicians," Workplace Health \& Safety, 63(9), 399-407, 2015. 